\title{
Field and CFD Study of Fuel Distribution in Pulverized Fuel (PF) Boilers
}

\section{CIUKAJ Szymon”, HERNIK Bartłomiej}

Institute of Power Engineering and Turbomachinery, Silesian University of Technology (SUT), Konarskiego 20, 44-101 Gliwice, Poland

(C) The Author(s) 2020

\begin{abstract}
The article presents both field and CFD results of a new concept of a mechanical pulverized fuel (PF) distributor. The goal of the study was to improve the pulverized coal-air mixture separation in PF boilers where the fuel preparation and feeding system was operated in a combined coal and biomass grinding conditions. The numerical analysis was preceded after a field study, where measurements were carried out in a pulverized coal-fired (PC) boiler equipped with a technology of $\mathrm{NO}_{x}$ reduction by means of primary methods. Proper distribution of a pulverized coal-air mixture to the individual burners is one of the fundamental tasks of the combustion systems where the primary methods are implemented to control the $\mathrm{NO}_{x}$ emission. Problems maintaining the proper distribution of fuel to the burners related primarily to the boilers where the coal and biomass co-grinding is used. Changing the load of coal-mills and fuel type at the same time (i.e., different types of biomass) could result in less effective separation of pulverized fuel particles in PF distributors. Selection of an appropriate construction of a distributor will allow the better control of the combustion process which results in decreased $\mathrm{NO}_{x}$ emission while keeping the proper combustion efficiency, i.e., less unburned carbon (UBC) in the fly ash. The results of the field measurements made it possible to create a CFD distribution base model, which was used for the analysis of a new splitter construction to be used in a PF distributor. Subsequent analysis of the numerical splitter enables precise analysis of its construction, including the efficiency of separation and the prediction of conveying of the coal and biomass particles.
\end{abstract}

\section{Keywords: pulverized fuel (PF) boiler, $\mathrm{NO}_{x}$ reduction, biomass co-firing, fuel distribution}

\section{Introduction}

Hard coal is the least expensive fossil fuel used for power generation in Poland. More than $90 \%$ of power units are fired with the pulverized coal. The coal combustion contributes to a serious air pollution [1,2], such as $\mathrm{NO}_{x}, \mathrm{SO}_{x}, \mathrm{CO}_{2}$ and dust. New, clean coal technologies are developed to meet environmental requirements for allowable emission limits. Most of the clean technologies imply oxy-fuel combustion $[3,4]$, switch to
Circulating Fluidized Bed (CFB) technology or construction of air quality control installation capable of treating the flue gas from a number of power units. Most of the 100 to $300 \mathrm{MW}_{\mathrm{e}}$ coal burning units in Poland were built in the 70's as subcritical units, and it is more economically reasonable to implement a low cost combustion control process for better efficiency and further implementation of flue gas treatment unit. The subject of the present study is to develop a new design of a pulverized fuel shutter divider that can operate more 
efficiently in a PF duct of boilers that are equipped with the $\mathrm{NO}_{x}$ primary reduction technologies. The work attempts to seek the proper fuel distribution to the burners in boilers while co-firing biomass of different types. A wide range of biomass (i.e., wood chips, pellets, straw briquette, fruit residues, agricultural biomass) fed to the PC boilers causes changing operating conditions of coal mills [5]. Every mill's load (i.e., minimum, avarage, maximum) requires a corresponding volume of drying agent that is also a PF conveying medium. While changing the biomass type being fed to the coal mill, its load affects the velocities of PF particles inside the PF ducts and as a result reduces the efficiency of the fuel distribution in the PF distributors. The present report gives a detailed description of field tests of fuel distribution while coal and coal with biomass co-milling. Test results give a required input data for a CFD model for a new construction design of a mechanical shutter to be used in the PF distributor. The first part of the report presents the measurement results of the fuel distribution in existing PF ducts equipped with a traditional PF distributors (i.e., designed to hard coal conveying conditions). Obtained data for coal and coal with biomass distribution results are used to create a base distribution CFD model to analyze new construction designs of a shutter divider. The method enables precise construction analysis including distribution efficiency and also biomass particles conveying conditions.

\section{Fuel Distribution in Low-NO Technology}

EU $\mathrm{NO}_{x}$ emission standards can be achieved by suitable, constructional, or operational modifications in the firing system of the boiler [6]. One of the key parameters is a proper selection of the burner outlet velocity and streams proportion of the primary and secondary air as well as managing the distribution of PF streams to the burners by means of the PF distributors. Reduction of $\mathrm{NO}_{x}$ emissions should be performed to keep the boiler thermal efficiency with calculation presented in Refs. [7, 8] thus preventing the formation of excessive amounts of $\mathrm{CO}$ and increased content of unburned carbon in the fly ash. It can be achieved mainly by means of the primary reducing methods held within the furnace. Technical solutions use two basic processes:

(1) Air staging (with separated Over Fire Air (OFA) levels) reduces emissions of nitrogen oxides by reducing the formation of $\mathrm{NO}_{x}$ in areas with reduced oxygen concentration (Fig. 1). In the figure, $\lambda$ means the excess air ratio.

(2) Air and fuel staging reduces $\mathrm{NO}_{x}$ to $\mathrm{N}_{2}$ by reducing nitrogen oxides formed in the first stage of combustion (Fig. 2 and Fig. 3).

In the PF boilers, it is relatively easy to provide a system of reducing emissions of nitrogen oxides based on the use of varying concentrations of coal dust-air mixtures at various levels of burners. The principle of such a system implemented in $500 \mathrm{MW}_{\text {th }} \mathrm{PF}$ power boiler is presented in Fig. 4 and Fig. 5.

Studies [9] have shown that the maximum amount of $\mathrm{NO}_{x}$ is yielded when the ratio of primary air to coal is about 3 to $4 \mathrm{~kg} / \mathrm{kg}$; this amount corresponds to the stoichiometric condition for the combustion of volatile matter. Below this value, the amount of $\mathrm{NO}_{x}$ is reduced due to shortage of oxygen and above due to the reduced

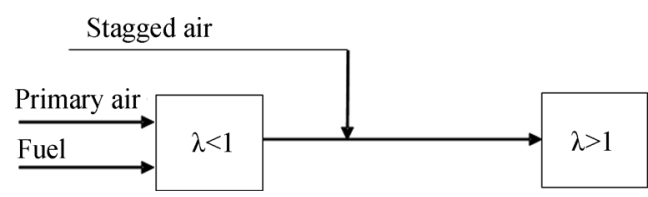

Fig. 1 Principle of $\mathrm{NO}_{x}$ reducing by means of air staging

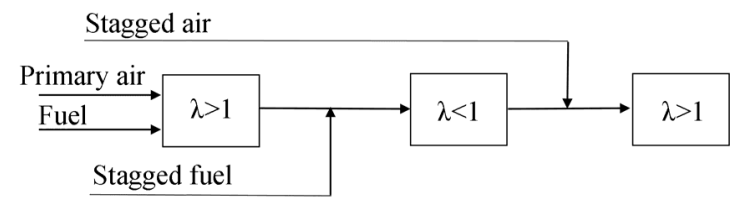

Fig. 2 Principle of $\mathrm{NO}_{x}$ reducing by means of air and fuel staging

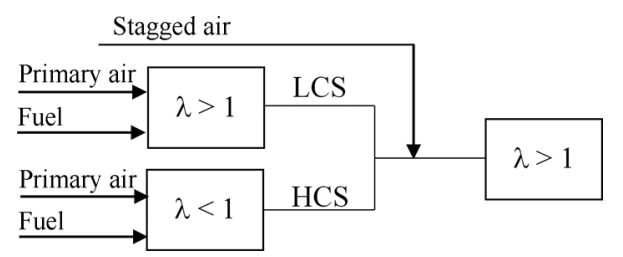

Fig. 3 Principle of $\mathrm{NO}_{x}$ reducing by means of air and fuel staging with different fuel concentration streams. LCS: low-concentrated fuel stream, HCS: highly concentrated fuel stream.

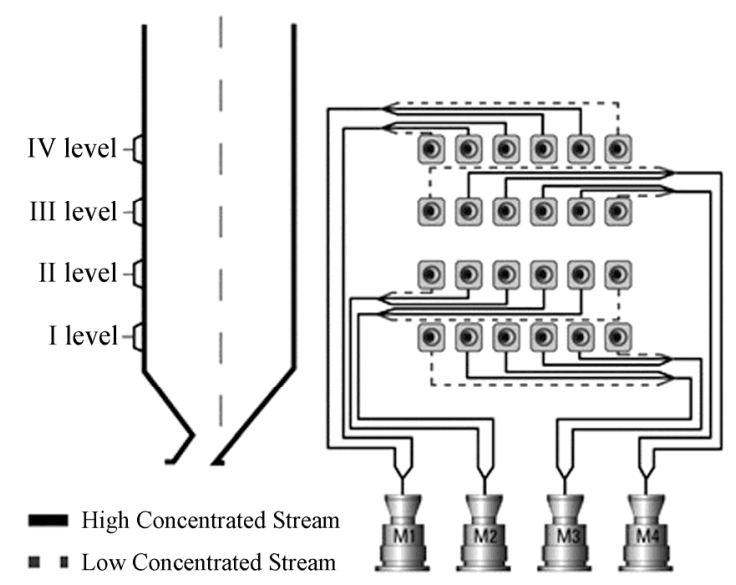

Fig. 4 Layout of the firing system of a PF boiler that uses a technology that can vary concentrations of fuel streams 
flame temperature. Thus, the $\mathrm{NO}_{x}$ emission is a weighted average of the quantities of nitrogen oxides formed during the combustion of the coal dust-air mixture of high and low concentrations.

The technology that varies concentrations of fuel streams has been applied in about 50 units of power boilers operated in Poland. There are different technical solutions that allow the fuel distribution, but shutter dividers (Fig. 6) provide the best distribution control. The operation idea is to divide the main PF stream into two separate streams where about $70 \%$ to $80 \%$ of the coal dust is handled to the burners in the lower rows of the furnace (i.e., highly concentrated fuel stream), and the remaining $20 \%$ to $30 \%$ of the coal dust is supplied to the burners in the upper rows (i.e., low concentrated fuel stream).

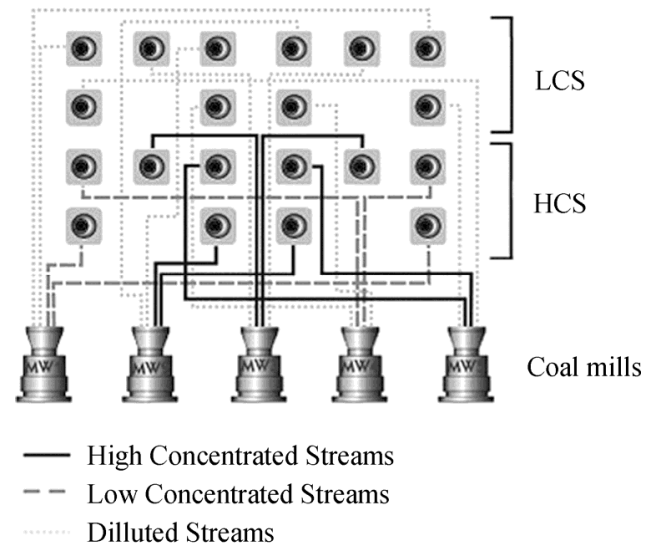

Fig. 5 Cross-staging of combustion stoichiometry in 500 $\mathrm{MW}_{\text {th }}$ boiler
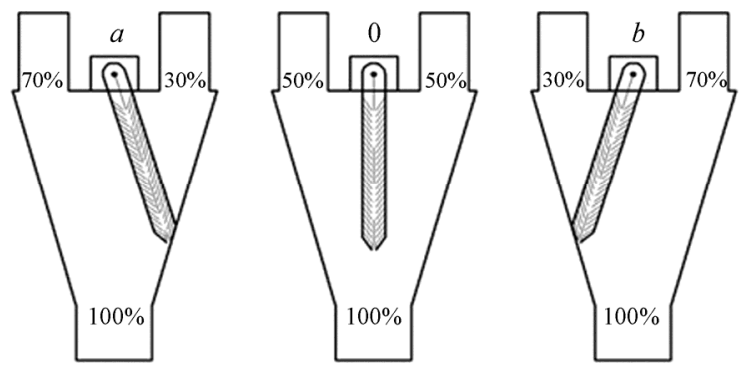

Fig. 6 The projected distribution of the fuel-air mixture depending on the position (i.e., $a, 0$, or $b$ ) of the shutter divider

\section{Field Test of Fuel Distribution in PF Distributions}

\subsection{Measurement method}

Optimization of the fuel combustion process in a PF boiler involves the control of the coal dust-air mixture distribution to the individual burners. Another key parameter is the fuel grinding quality achieved in the coal grinding system. In the measurement practice an extraction procedure is widely used. It involves a periodic aspiration of coal dust-gas mixture samples from the coal dust ducts and separation of solid fuel particles and gaseous phases so as to determine their masses. To assess the quality of the coal dust, the basic method of sieve analysis is used. A detailed description of determining the quality of the milling is described in Ref. [5]. In boiler technology, sieve analysis is performed for two screen sizes- $\mathrm{R}_{0,09}$ and $\mathrm{R}_{0,20}$-for which a Rosin-Rammler-Sperling diagram (RRS) is prepared. From the RRS diagram, the number of polydispersity can be read, which is characterized by a degree of uniformity of the coal dust particles. The higher it is, the coal dust is closer to being monodisperse; this means that the coal dust is composed of particles of equal size. For greater combustion efficiency, it is preferable to prepare finer coal dust, but this will be affected by increased erosive wear of grinding elements, and more energy is required to prepare the coal dust. General scheme of the measuring system is shown in Fig. 7 where the dynamic pressure measurement points and the dust sampling point are indicated. Samples of coal dust are collected by the isokinetic suction device which includes the following: aspiration probe, heated de-dusting cyclone, venturi nozzle, squeegee, the control valve, and connecting cables as described in Ref. [5].

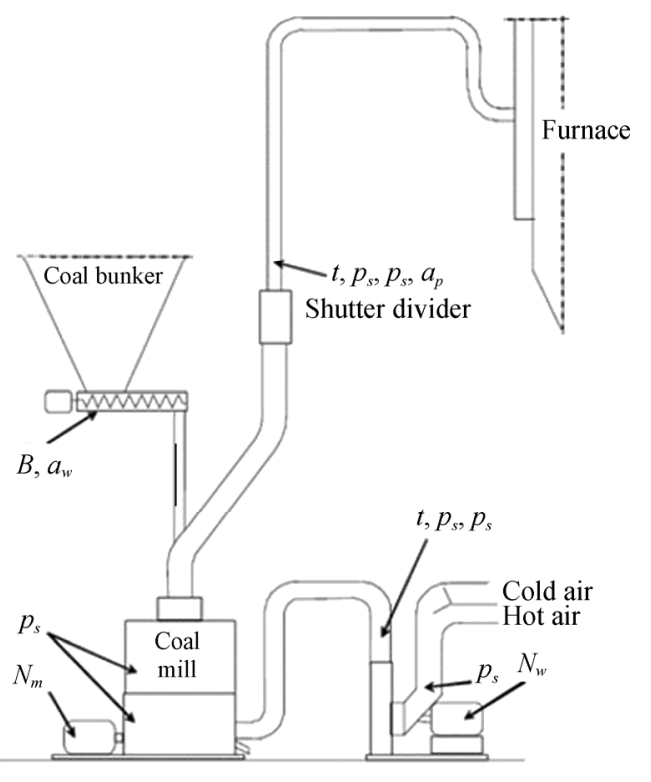

$t$ - temperature measurement points, $p_{s}$ - static pressure measurement points, $p_{d}-$ dynamic pressure measurement points, $N_{w}$ - measured power consumption of mill's fan motor, $N_{m}$ measured power consumption of coal mill's motor, $B$ - measured raw coal feeder capacity, $a_{w}$ - raw coal sampling point, $a_{p}-$ pulverized coal sampling point.

Fig. 7 Scheme of the measuring set of coal mill unit 
Adding wet biomass to be grounded with coal in coal mills increases the moisture content of the coal dust-air mixture from the mill and decreases its temperature. In some cases, the problem can be compensated by increasing ventilation and inlet air temperature. Increasing the amount of primary air and the need to work with open separator blades involves a change of operating conditions in such a mill thus influencing the distribution efficiency in shutter dividers mounted inside the coal dust ducts.

Fig. 8 presents the view of a mixture of coal and wood chips in the form of pellets and grains of oats. In Fig. 9 the sample of pulverized coal and biomass during the sieve analysis is shown. To determine the effect of the addition of various biomass types on grinding quality and their impact on the operation of the shutter divider, the relevance of the research on the coal particle size distribution (PSD) measurements with the addition of biomass collected from selected boilers equipped with primary methods of $\mathrm{NO}_{x}$ reduction was performed. The measurements were conducted according to the method of isokinetic suction of coal dust samples, which were then subjected to particle size analysis. Based on the results of sieve analysis and coal dust concentration, it was possible to determine the efficiency of the shutter divider.

The results of the sieve analysis presented in Figs. 10 and 11 show the grinding quality of coal during different biomass types and different mass fraction of biomass in total fuel stream. Samples were taken from the dust duct of a ring-ball mill by means of isokinetic sampling, according to Ref. [5]. Sieve analysis was performed using standard methods described in Ref. [5]. The RRS diagram illustrates points of residue on each screen for homogeneous substances; all should lie on a straight line, and the slope depicts the number of polydispersity. For hard coal, even though it is not a homogeneous substance, the deviation of points obtained from measurements is insignificant. However, for a mixture of coal with biomass, the RRS diagram can be divided into two distinct sections. Points obtained to the residue of $0.2 \mathrm{~mm}$ screen size are arranged with a high accuracy obtaining polydispersity numbers in the range of $0.9-1.2$. This is the same range as obtained by milling of hard coal.

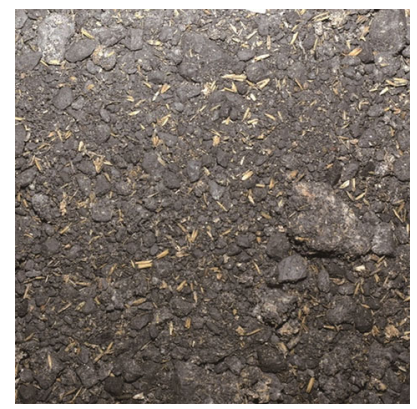

Fig. 8 View of raw coal and biomass being fed to the coal mill

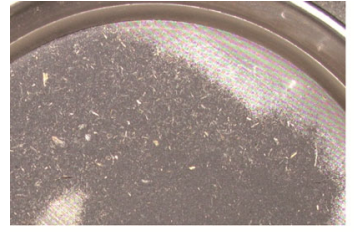

(a) on the screen $\mathrm{R}_{0,09}$

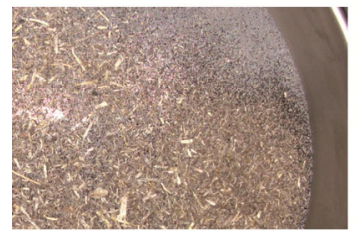

(c) a sieve $R_{0,5}$

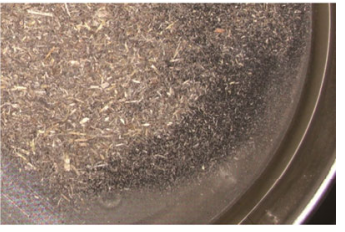

(b) a sieve $\mathrm{R}_{0,2}$

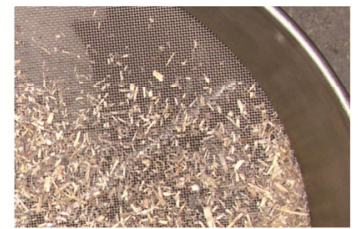

(d) in a sieve $R_{1,0}$
Fig. 9 View of sieve residue of coal with biomass sample

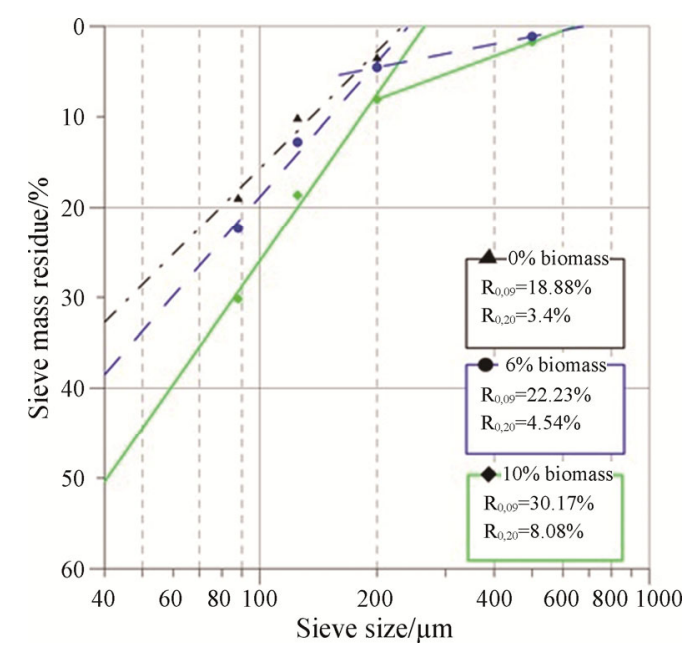

Fig. 10 Particle Size Distribution (PSD) of coal dust and coal with biomass mixture dust (forest wood chips biomass by mass share $0 \%, 6 \%$ and $10 \%$ respectively)

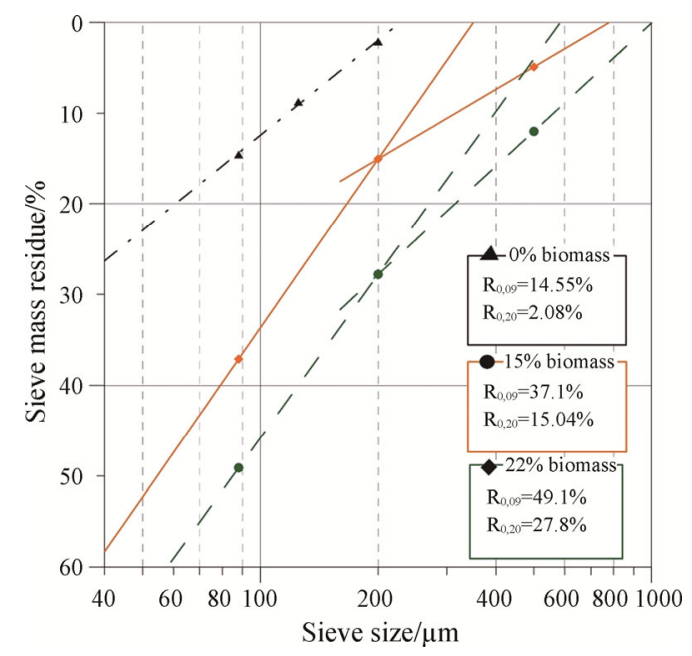

Fig. 11 PSD of coal dust and coal with biomass mixture dust (sunflower husk biomass by mass share $0 \%, 15 \%$ and $22 \%$ respectively) 
Points measured for the screen size $>0.5 \mathrm{~mm}$ also form a line but at much lower angles of inclination. Presented field tests showed that the coal and biomass mixtures form a separate size distribution and is presented in the RRS diagrams as lines intersecting each other. The points of intersection of these lines indicate that the fuel particles larger than $0.2 \mathrm{~mm}$ are biomass particles, and below $0.2 \mathrm{~mm}$ the mass is determined by the residue of coal dust. Inhomogeneity in terms of grain size is confirmed by the residues results shown in Fig. 9 where for screen size $>0.2 \mathrm{~mm}$ almost exclusively biomass particles are present. The particle size distribution of coal dust produced from a mixture of coal with biomass, which differs substantially from the coal dust particles, causes changes in the combustion process that meet the

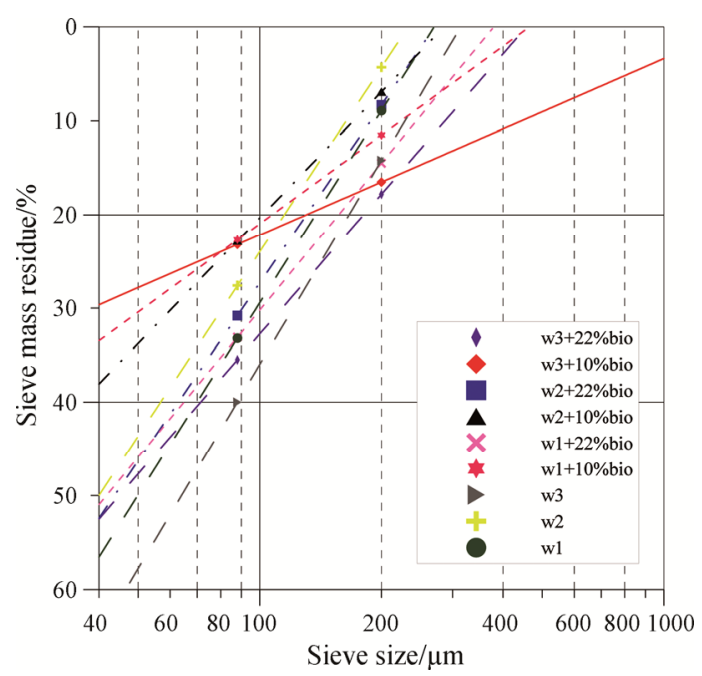

Fig. 12 PSD of the mixture of coal dust from the ring-ball mill of a boiler under regular operation (i.e., without low- $\mathrm{NO}_{x}$ technology; biomass mass share $=10 \%$ and $22 \%$ )

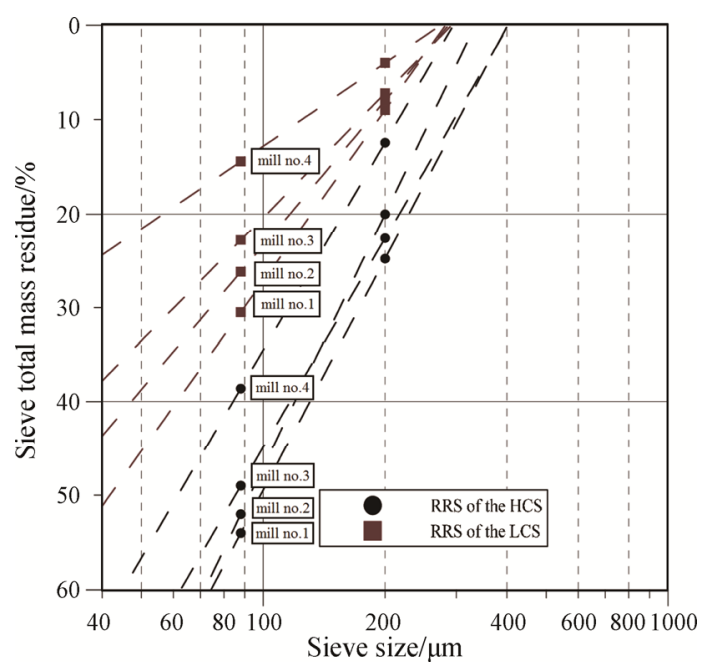

Fig. 13 Size distribution of low-concentrated (LCS) and highly concentrated (HCS) fuel streams in boiler equipped with 4 coal mills need to adapt the operation of the boiler to the changed conditions. This is particularly important in the case of boilers equipped with low- $\mathrm{NO}_{x}$ systems with varying concentrations of fuel stream (Fig. 5). The results of the sieve analysis carried out for the installation of the boiler equipped with a low- $\mathrm{NO}_{x}$ installation using varying concentrations of fuel stream is shown in Fig 13. For comparison, Fig. 12 shows the results of sieve analysis of dust collected from the boiler that was operated under normal operating conditions where strict $\mathrm{NO}_{x}$ emission is not required. The marks w1, w2, and w3 mean the dust samples collected from coal mill no1, no2 and no3 respectively.

\subsection{Scope of field measurements}

The measurements were performed under on-line operation of the ring-ball mills. Mills were fed with either hard coal or coal with biomass (mass share $=22 \%$ ). For individual mills the following tests were performed:

- Measurements of fuel distribution and ventilation in PF ducts after the shutter dividers;

- Measurement of grinding quality of the produced coal dust;

- Measurements by the average fuel load of the Maximum Continuous Rating $(60 \% \mathrm{MCR})$ of the mill where the shutter divider was set to highlyconcentrated stream to the lower row of burners;

- Measurements by the average fuel load (60\%MCR) of the mill where the shutter divider was set to three different positions (i.e., highly-concentrated stream to the lower row of burners, equal distribution of coal dust between lower and upper row of burners, and the highly-concentrated stream set to the upper row of burners);

- Measurements by the average fuel load (60\%MCR) of the mill while changing the grinding quality (i.e., different separator's blades set);

- Measurements by the maximum fuel load $(90 \% \mathrm{MCR})$ of the mill while changing the ventilation.

Measurement of the flow rate of coal dust-gas mixture in the individual PF ducts were performed using pitot probe, a WTI probe, and a U-tube. Coal dust samples were collected according to PN-91/M-34141, and fuel particle size distribution analysis were done with a sieve screen sizes 88 micrometre $(\mu \mathrm{m}), 200 \mu \mathrm{m}$, and $500 \mu \mathrm{m}$.

\subsection{Fuel distribution measurement results}

Table 1 shows selected key parameters obtained from the measurements of the mills.

In the conducted tests, the mills steering separator blades were adjusted to provide the data of influence on grinding quality. The steering angle set was $25^{\circ}-45^{\circ}$.

In conclusion, it can be said that the impact of separator's operation on the coal dust separation is very clear (Tables 2 and 3, Fig. 14). It allows to maintain the 
Table 1 Grinding quality of coal mills

\begin{tabular}{|c|c|c|c|c|c|c|}
\hline \multirow{2}{*}{ Mill no } & \multirow{2}{*}{$\begin{array}{c}\text { Fuel load/ } \\
\mathrm{t} \cdot \mathrm{h}^{-1}\end{array}$} & \multicolumn{2}{|c|}{ Ventilation } & \multicolumn{3}{|c|}{ Sieve analysis, $\%$} \\
\hline & & $\mathrm{m}_{\mathrm{n}}{ }^{3} / \mathrm{h} \times 10^{3}$ & $\mathrm{~m}^{3} / \mathrm{h} \times 10^{3}$ & $\mathrm{R}_{0.09}$ & $\mathrm{R}_{0.2}$ & $\mathrm{R}_{0.5}$ \\
\hline 1 & 19.9 & $36.6-37.2$ & $50.0-50.3$ & $43.9-49.5$ & $17.7-21.8$ & $5.0-6.4$ \\
\hline 2 & $19.6-28.6$ & $39.1-49.3$ & $54.6-65.5$ & $39.7-52.3$ & $15.1-26.8$ & $3.8-8.4$ \\
\hline 3 & 18.6 & $45.3-45.9$ & $62.5-63.9$ & $39.4-46.0$ & $13.0-18.4$ & $3.2-5.1$ \\
\hline 4 & $20.6-27.5$ & $40.7-49.7$ & $57.0-67.8$ & $40.9-50.6$ & $16.1-25.4$ & $5.0-8.8$ \\
\hline 5 & $18.7-27.0$ & $43.2-47.4$ & $60.4-65.5$ & $39.2-50.2$ & $17.1-24.2$ & $5.5-7.2$ \\
\hline 6 & $19.9-28.8$ & $44.5-47.1$ & $61.1-64.3$ & $33.2-46.0$ & $11.8-21.1$ & $2.8-7.0$ \\
\hline
\end{tabular}

Table 2 Influence of separator's blades set on grinding quality of coal mills

\begin{tabular}{|c|c|c|c|c|c|}
\hline & & unit & \multicolumn{3}{|c|}{ Coal mill no.2 } \\
\hline \multicolumn{2}{|c|}{ Separator blades set } & o & 25 & 35 & 45 \\
\hline \multirow{3}{*}{$\begin{array}{c}\text { Grinding } \\
\text { quality }\end{array}$} & Screen size $\mathrm{R}_{0.09}$ & $\%$ & 52.3 & 43.4 & 41.0 \\
\hline & Screen size $\mathrm{R}_{0.2}$ & $\%$ & 26.8 & 16.4 & 17.6 \\
\hline & Screen size $\mathrm{R}_{0.5}$ & $\%$ & 8.4 & 3.8 & 4.4 \\
\hline & & unit & \multicolumn{3}{|c|}{ Coal mill no.3 } \\
\hline \multicolumn{2}{|c|}{ Separator blades set } & o & 30 & 35 & 40 \\
\hline \multirow{3}{*}{$\begin{array}{c}\text { Grinding } \\
\text { quality }\end{array}$} & Screen size $\mathrm{R}_{0.09}$ & $\%$ & 46.0 & 40.8 & 39.4 \\
\hline & Screen size $\mathrm{R}_{0.2}$ & $\%$ & 18.4 & 14.0 & 13.0 \\
\hline & Screen size $\mathrm{R}_{0.5}$ & $\%$ & 5.1 & 3.5 & 3.2 \\
\hline & & unit & \multicolumn{3}{|c|}{ Coal mill no.4 } \\
\hline \multicolumn{2}{|c|}{ Separator blades set } & o & 30 & & 40 \\
\hline \multirow{3}{*}{$\begin{array}{c}\text { Grinding } \\
\text { quality }\end{array}$} & Screen size $\mathrm{R}_{0.09}$ & $\%$ & 47.2 & & 40.9 \\
\hline & Screen size $\mathrm{R}_{0.2}$ & $\%$ & 19.8 & & 16.1 \\
\hline & Screen size $\mathrm{R}_{0.5}$ & $\%$ & 5.0 & & 5.5 \\
\hline & & unit & \multicolumn{3}{|c|}{ Coal mill no.5 } \\
\hline \multicolumn{2}{|c|}{ Separator blades set } & o & 30 & & 40 \\
\hline \multirow{3}{*}{$\begin{array}{l}\text { Grinding } \\
\text { quality }\end{array}$} & Screen size $\mathrm{R}_{0.09}$ & $\%$ & 50.2 & & 39.2 \\
\hline & Screen size $\mathrm{R}_{0.2}$ & $\%$ & 24.2 & & 18.2 \\
\hline & Screen size $\mathrm{R}_{0.5}$ & $\%$ & 7.2 & & 5.6 \\
\hline & & unit & \multicolumn{3}{|c|}{ Coal mill no. 6} \\
\hline \multicolumn{2}{|c|}{ Separator blades set } & o & 30 & & 40 \\
\hline \multirow{3}{*}{$\begin{array}{c}\text { Grinding } \\
\text { quality }\end{array}$} & Screen size $R_{0.09}$ & $\%$ & 46.0 & & 35.8 \\
\hline & Screen size $R_{0.2}$ & $\%$ & 21.1 & & 13.6 \\
\hline & Screen size $\mathrm{R}_{0.5}$ & $\%$ & 7.0 & & 3.9 \\
\hline
\end{tabular}

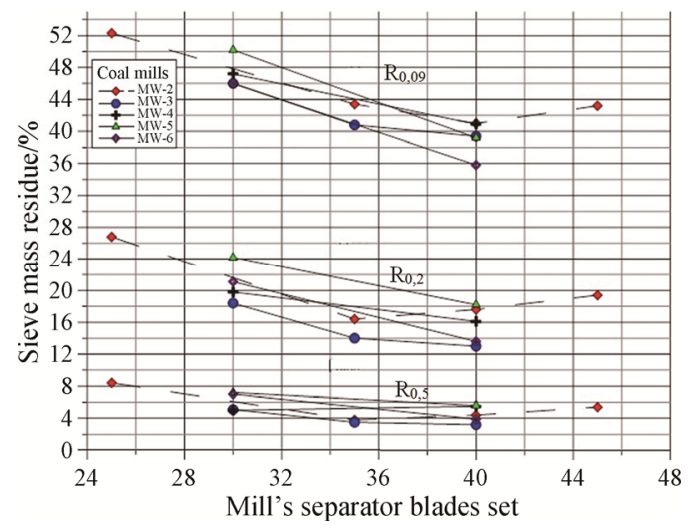

Fig. 14 Illustration of influence of separator's blade set on grinding quality of the mill
Table 3 Influence of shutter divider on the fuel distribution

\begin{tabular}{|c|c|c|c|c|c|}
\hline & & \multirow[t]{2}{*}{ unit } & \multicolumn{3}{|c|}{ Coal mill no.1 } \\
\hline \multicolumn{2}{|c|}{ Shutter divider set } & & $a$ & 0 & $b$ \\
\hline \multirow{2}{*}{$\begin{array}{c}\text { Fuel } \\
\text { distribution }\end{array}$} & HCS & $\%$ & 69.8 & 52.7 & 43.6 \\
\hline & LCS & $\%$ & 30.2 & 47.3 & 56.4 \\
\hline & & & \multicolumn{3}{|c|}{ Coal mill no.4 } \\
\hline \multicolumn{2}{|c|}{ Shutter divider set } & & $a$ & 0 & $b$ \\
\hline \multirow{2}{*}{$\begin{array}{c}\text { Fuel } \\
\text { distribution }\end{array}$} & HCS & $\%$ & 67.9 & 56.4 & 44.2 \\
\hline & LCS & $\%$ & 32.1 & 43.6 & 55.8 \\
\hline & & & \multicolumn{3}{|c|}{ Coal mill no.5 } \\
\hline \multicolumn{2}{|c|}{ Shutter divider set } & & $a$ & 0 & $b$ \\
\hline \multirow{2}{*}{$\begin{array}{c}\text { Fuel } \\
\text { distribution }\end{array}$} & HCS & $\%$ & 67.8 & 51.8 & 34.8 \\
\hline & LCS & $\%$ & 32.2 & 48.2 & 65.2 \\
\hline & & & \multicolumn{3}{|c|}{ Coal mill no.6 } \\
\hline \multicolumn{2}{|c|}{ Shutter divider set } & & $a$ & 0 & $b$ \\
\hline \multirow{2}{*}{$\begin{array}{c}\text { Fuel } \\
\text { distribution }\end{array}$} & HCS & $\%$ & 67.9 & 50.7 & 33.1 \\
\hline & LCS & $\%$ & 32.1 & 49.3 & 66.9 \\
\hline
\end{tabular}
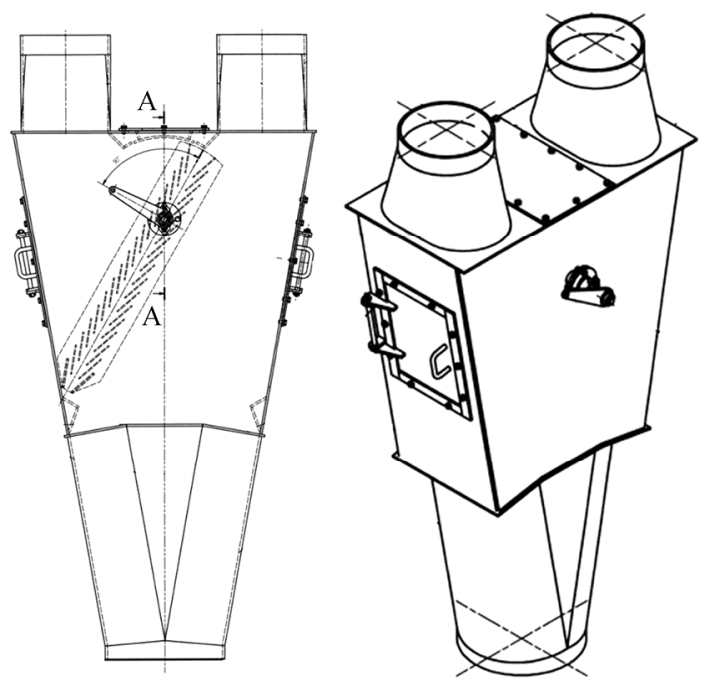

Fig. 15 The shutter divider of pulverized coal - isometric view with cross-section

control of operating parameters of the mill within the grinding quality control.

The shutters divider of pulverized coal (Fig. 15) is placed in the way of the air-coal mixture behind the mill's separator. Its duty is to divide the pulverized 
air-coal mixture into separated highly concentrated and low-concentrated pulverized coal streams.

The shutter functioned as a divider. It is comprised of blades placed in relation to the shutters' axes with a proper angle. Width of blades $b$, interval between blades $s$, and angle between blades $\alpha$, all have influence on the dividers function (Fig. 16).

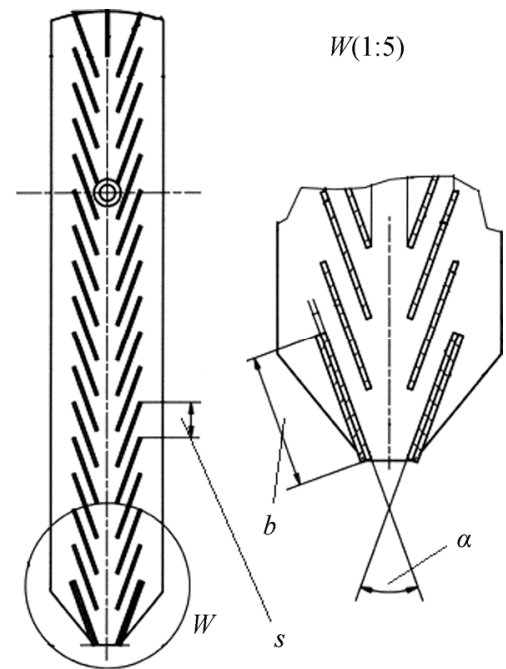

Fig. 16 The shutter of divider with characteristic dimensions

First, numerical calculations were carried out, validated by measurements on the real object. A maximum relative error of $10 \%$ was achieved between the results obtained from numerical calculations and measurements. Then, the different modernizations of the shutters of dividers were simulated. The purpose of the work was to find a variant of modernization for which the mass fraction of concentrated pulverized coal at the outlet would be the largest. Studies on the separation process have been numerous in recent years. The paper [10] presents the research on the flow profile in the dust channel of the mill system of a pulverized coal power plant. Experimental and computational studies on the efficiency of the cross-separator are presented in Ref. [11]. The results allowed optimizing and improving the geometry and efficiency of the separator. In Ref. [12] the results of research on a gravity separator installed in a sand factory for separating crumbled rock material into a fine particle fraction and a coarse particle fraction are presented. Using the Eulerian-Eulerian method instead of the Eulerian-Lagrangian approach to calculate the separators shortens the calculation time; however, the dynamics of individual particles cannot be estimated [13]. Research on the wall collision model and restitution coefficients was shown in Ref. [14]. In Ref. [15] on the basis of laboratory tests of the separator, numerical flow of the gas phase was modeled by selecting the appropriate turbulence model.

\section{Numerical Model and Boundary Conditions}

In a commercial CFD program Ansys Fluent a geometrical model with a numerical mesh was created, as shown in Figs. 17, 18, and 19. In the regions of the outlet of the model and the inlet flow to the divider a structural mesh is used. However, the tetragonal mesh is used for the shutter and the block of divider. The numerical mesh composed of 561897 numerical cells and 128203 nodes. The air and pulverized coal flow was calculated with two-phase Euler-Lagrange model [16-21]. Via surface of

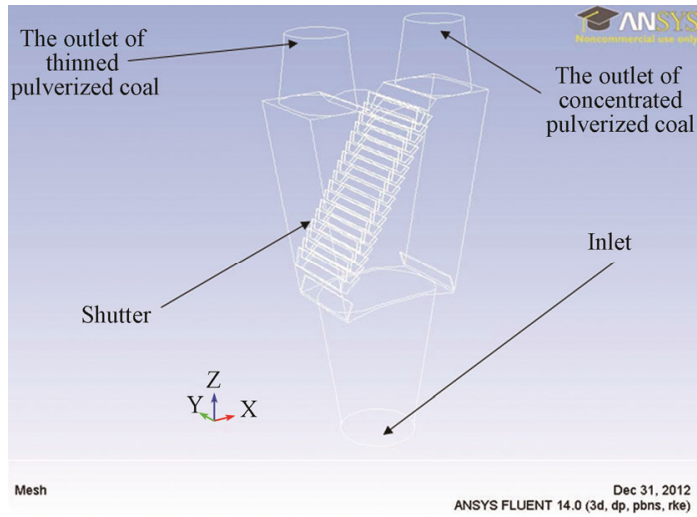

Fig. 17 Geometry of PF distributor

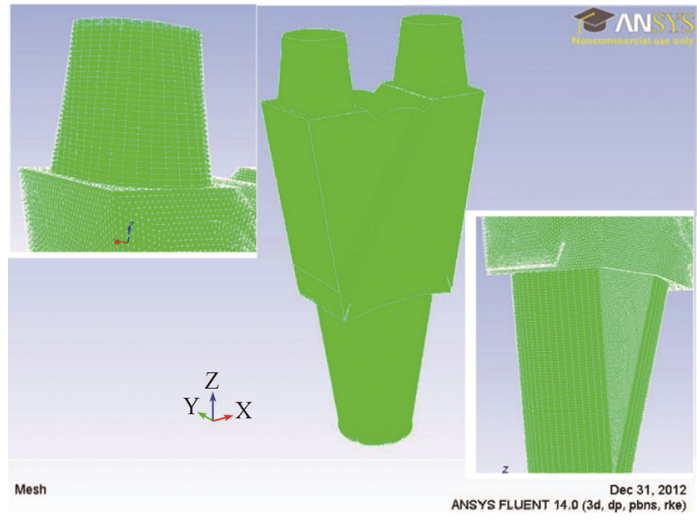

Fig. 18 Numerical mesh of PF distributor

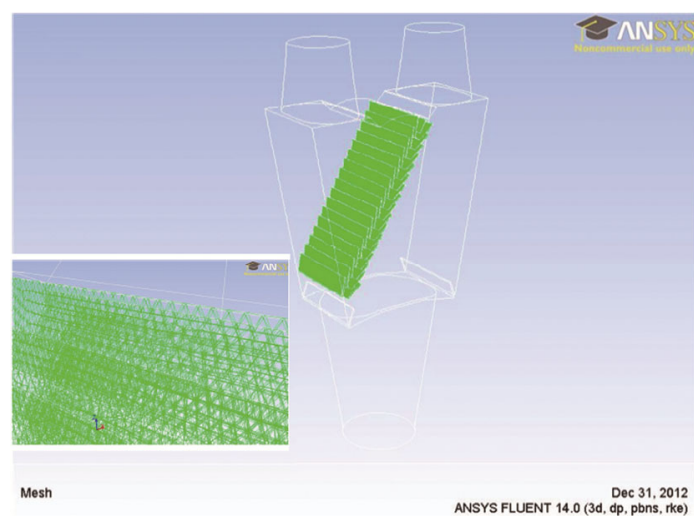

Fig. 19 Numerical mesh of shutters inside the PF distributor 
inlet in the model the pulverized-coal particle was injected. The particle-particle interactions were not considered. The steady state calculation was done. The two-way coupling approach was used to simulate the effect of the particle on the continuous phase flow. The impact of the particle on the wall of the shutter was treated as reflected. It is necessary to apply normal and tangential restitution coefficients to predict the trajectory of the reflected particles [22]. In the laboratory at the Division of Boilers and Steam Generators the restitution coefficients were experimentally determined. The SIMPLE method was used as the pressure-velocity coupling method. The turbulent model k- $\epsilon$ real with nonequilibrium wall functions was selected to take into account the influence of the pressure gradients [15, 23, 24, 25]. The Rosin-Rammler-Sperling distribution was selected and the spherical shape of pulverized coal was chosen [26]. The validation of the numerical model with the results of measurements on the actual object was the first stage of our study. The boundary conditions of the numerical model come from measurements was showed in Table 4.

A grid-independence study for a Case 2 from Table 4 was done to check the adequacy of the applied grid resolution. For further calculations, the average grid was chosen due to the good consistency of the results obtained on it in comparison with the measurements. Calculations have not been made on the fine mesh due to hardware and time constraints. Symbols $m_{a}$, and $m_{c}$ mean air and coal flow. $X_{c}$ means the percentage distribution of pulverized coal for the concentrated and thinned outlet

\subsection{Validation of the CFD model}

For the boundary conditions of the nine cases from Table 4, numerical modeling was carried out. The results of the calculations should confirm that, similarly to the real object, the shutter separated pulverized coal from the air-coal mixture to concentrated and thinned pulverized coal streams in the CFD model. These calculations have confirmed the validity of selected numerical assumptions. Particular numbers of measurements correspond to the variant of numerical calculations. Below, the exemplary results of a numerical modeling for Case 1 from Table 4 were presented to confirm the field distribution results for " $a$ " and " $b$ " cases presented in Table 3 .

\subsection{Modernization of the shutter}

As the results obtained from CFD modeling do not differ significantly from those obtained from the measurements, the chosen numerical assumptions were considered appropriate and modeling of the modernization of the distributor was started. Table 5 shows the calculations made for Case 2 from Table 4. The following cases of the divider modernization were modeled:

(1) Angle between blades $\alpha$ (Fig. 16) was changed from $40^{\circ}$ (base case) to $50^{\circ}$.

(2) Angle between blades $\alpha$ (Fig. 16) was changed from $40^{\circ}$ (base case) to $60^{\circ}$.

(3) Angle between blades $\alpha$ (Fig. 16) was changed from $40^{\circ}$ (base case) to $30^{\circ}$.

(4) Angle between blades $\alpha$ (Fig. 16) was changed from $40^{\circ}$ (base case) to $20^{\circ}$.

Table 4 Boundary conditions of numerical model reached from measurements

\begin{tabular}{|c|c|c|c|c|c|c|c|c|c|c|c|}
\hline \multicolumn{3}{|c|}{ Number of measurements/case } & 1 & 2 & 3 & 4 & 5 & 6 & 7 & 8 & 9 \\
\hline \multicolumn{3}{|c|}{ Pulverized fuel } & $\begin{array}{c}\text { coal + } \\
\text { biomass }\end{array}$ & coal & coal & coal & coal & coal & coal & coal & coal \\
\hline \multicolumn{3}{|c|}{ Position of shutter } & \multicolumn{6}{|c|}{ extreme $(a, b)$} & \multicolumn{3}{|c|}{ central $(0)$} \\
\hline Pulverized coal flow & $m_{c}$ & $\mathrm{~kg} / \mathrm{s}$ & 3.39 & 3.28 & 2.94 & 3.7 & 2.55 & 3.37 & 2.76 & 2.85 & 2.8 \\
\hline \multirow[t]{2}{*}{ Air flow } & $m_{a}$ & $\mathrm{~kg} / \mathrm{s}$ & 10.66 & 14.28 & 10.55 & 15.66 & 12.1 & 16.8 & 11.74 & 16.09 & 15.99 \\
\hline & $\mathrm{R}_{0.09}$ & $\%$ & 49.3 & 17.2 & 47.2 & 49.4 & 39.2 & 45.3 & 46 & 40.8 & 39.4 \\
\hline \multirow[t]{2}{*}{ Average remains on sieve } & $\mathrm{R}_{0.2}$ & $\%$ & 19.5 & 2.1 & 19.8 & 25.4 & 18.2 & 20.1 & 18.4 & 14 & 13 \\
\hline & $\mathrm{R}_{0.5}$ & $\%$ & 8.7 & 0 & 5 & 8.8 & 5.6 & 6.1 & 5.1 & 3.5 & 3.2 \\
\hline
\end{tabular}

Table 5 The grid-independence study results

\begin{tabular}{|c|c|c|c|c|c|c|c|c|c|c|c|}
\hline \multirow{2}{*}{$\begin{array}{c}\text { Case } 2 \\
\text { Data }\end{array}$} & \multicolumn{2}{|c|}{ Measurement } & \multicolumn{2}{|c|}{ CFD coarse mesh } & \multirow{2}{*}{$\begin{array}{c}\text { Error } \\
-\end{array}$} & \multicolumn{2}{|c|}{ CFD medium mesh } & \multirow{2}{*}{$\begin{array}{c}\text { Error } \\
-\end{array}$} & \multicolumn{2}{|c|}{ CFD fine mesh } & \multirow{2}{*}{$\begin{array}{c}\text { error } \\
-\end{array}$} \\
\hline & $m_{c}$ & $X_{c}$ & $m_{c}$ & $X_{c}$ & & $m_{c}$ & $X_{c}$ & & $m_{c}$ & $X_{c}$ & \\
\hline Unit & $\mathrm{kg} / \mathrm{s}$ & $\%$ & $\mathrm{~kg} / \mathrm{s}$ & $\%$ & $\%$ & $\mathrm{~kg} / \mathrm{s}$ & $\%$ & $\%$ & $\mathrm{~kg} / \mathrm{s}$ & $\%$ & $\%$ \\
\hline $\mathrm{HCS}$ & 2.036 & 62.1 & 1.943 & 59.3 & 4.59 & 2.033 & 62.1 & 0.17 & 2.019 & 61.6 & 0.86 \\
\hline LCS & 1.244 & 37.9 & 1.335 & 40.7 & 7.33 & 1.243 & 37.9 & 0.06 & 1.259 & 38.4 & 1.22 \\
\hline Sum & 3.28 & 100 & 3.28 & 100 & - & 3.28 & 100 & - & 3.28 & 100 & - \\
\hline
\end{tabular}


Table 6 Results of CFD modelling (Case 1 from Table 4) and field measurement results.

\begin{tabular}{ccccccc}
\hline Case & \multicolumn{2}{c}{ CFD } & & \multicolumn{2}{c}{ Measurement } & Error \\
\cline { 2 - 3 } Data & $m_{c}$ & $X_{c}$ & & $m_{c}$ & $X_{c}$ & - \\
Unit & $\mathrm{kg} / \mathrm{s}$ & $\%$ & & $\mathrm{~kg} / \mathrm{s}$ & $\%$ & $\%$ \\
\hline HCS & 2.194 & 64.7 & & 2.203 & 65 & 0.39 \\
LCS & 1.196 & 35.3 & & 1.187 & 35 & 0.8 \\
Sum & 3.39 & 100 & & 3.39 & 100 & - \\
\hline
\end{tabular}

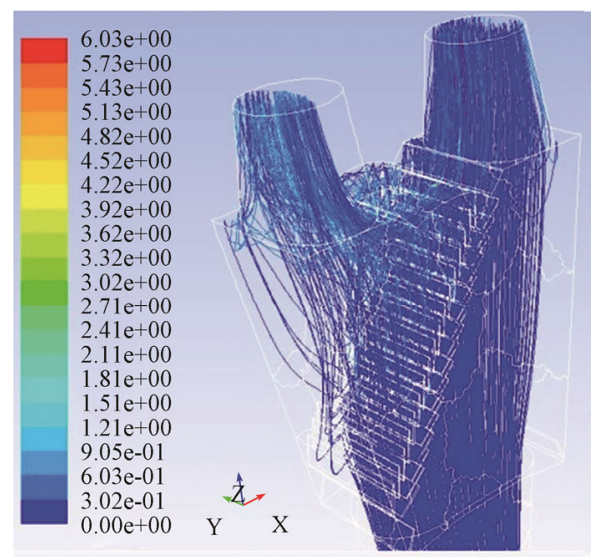

(a) particle residence time/s

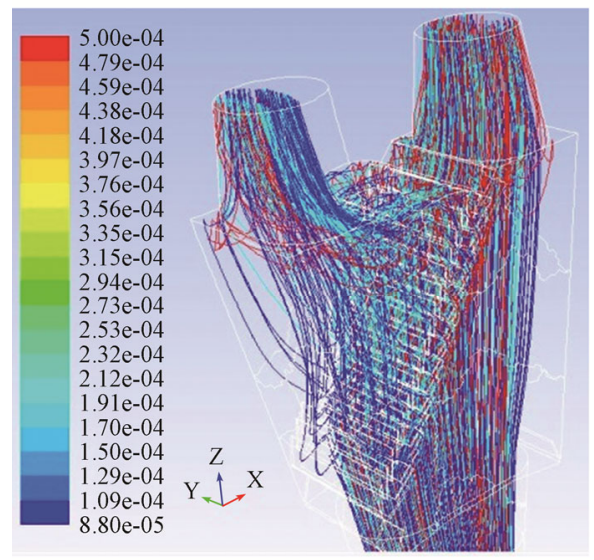

(b) particles diameter $/ \mathrm{m}$

Fig. 20 Distribution of pulverized coal to HCS stream (right outlet) and LCS stream (left outlet) is shown with particle residence time in the PF distributor (a) and particles diameter (b)

(5) Width of blades $b$ (Fig. 16) was changed from 150 (base case) to $200 \mathrm{~mm}$.

(6) Interval between blades $s$ (Fig. 16) was changed from 79 (base case) to $60 \mathrm{~mm}$.

(7) Width of blades $b$ (Fig. 16) was changed from 150 (base case) to $200 \mathrm{~mm}$ and interval between blades $s$ (Fig. 16) was changed from 79 (base case) to $60 \mathrm{~mm}$.

(8) Width of blades $b$ (Fig. 16) was changed from 150 (base case) to $200 \mathrm{~mm}$; interval between blades $s$ (Fig. 16) was changed from 79 (base case) to $60 \mathrm{~mm}$; and angle between blades $\alpha$ (Fig. 16) was changed from $40^{\circ}$ (base case) to $30^{\circ}$.

(9) Width of blades $b$ (Fig. 16) was changed from 150 (base case) to $200 \mathrm{~mm}$; interval between blades $s$ (Fig. 16) was changed from 79 (base case) to $60 \mathrm{~mm}$; and angle between blades $\alpha$ (Fig. 16) was changed from $40^{\circ}$ (base case) to $20^{\circ}$.

(10) Examination of the influence of the particles' velocity through the shutter on its efficiency (with base concentration of pulverized coal).

(11) Change of idea of shutter (i.e., blades in inverted array should be brought closer to the central axis; Fig. 21). In Fig. 21, $s$ means interval between blades; $h$ means slanting interval between blades.

(12) Change of idea of shutter (i.e., extended blades in inverted array should be closer to the central and cut axis; Fig. 21).

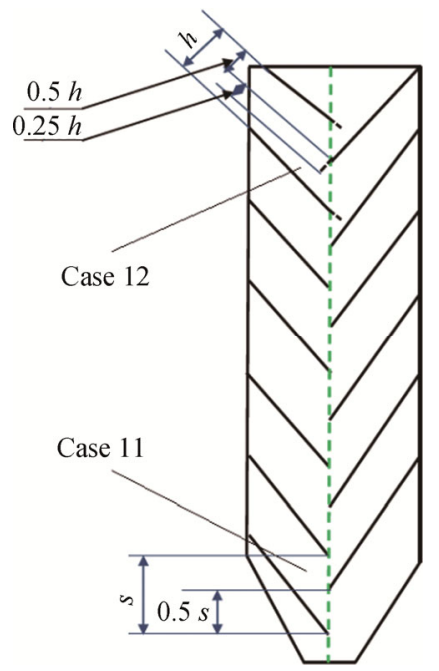

Fig. 21 Change of idea of shutter

Below, the results of numerical modeling for Case 10 are presented. We sought to examine the influence of the particles velocity through the shutter on its efficiency (with base concentration of pulverized coal). Two cases were modeled: decreasing and increasing the velocity of half the particles through the shutter. In Table 7, the results of the CFD model with the modernized dividers is shown. Decreasing the velocity of about half of the particles through the shutter makes a worse distribution of pulverized coal to the concentrated outlet $\Delta X_{c H C S}$ by approximately $2.59 \%$. This case did not improve the maximal mass fraction of pulverized coal to concentrated outlet. Increasing the velocity of particles through the shutter by about half makes a better distribution of pulverized coal to the concentrated outlet $\Delta X_{c H C S}$ by about $2.75 \%$. So, this case improves the maximal mass fraction of pulverized coal flowing to the concentrated outlet. Fig. 22 shows the distribution of pulverized coal in the divider along with particle velocity. 
Table 7 Results of CFD modelling of proposition of dividers modernization

\begin{tabular}{|c|c|c|c|c|c|c|c|c|c|c|c|c|}
\hline \multirow{2}{*}{$\begin{array}{l}\text { Case } \\
\text { Data }\end{array}$} & \multicolumn{4}{|c|}{ Base - measurement $w_{n}=20 \mathrm{~m} / \mathrm{s}$} & \multicolumn{4}{|c|}{$10 a, w_{n}=10 \mathrm{~m} / \mathrm{s}$} & \multicolumn{4}{|c|}{$10 b, w_{n}=30 \mathrm{~m} / \mathrm{s}$} \\
\hline & $m_{c}$ & $X_{c}$ & $V_{a}$ & $c_{c}$ & $m_{c}$ & $X_{c}$ & $V_{a}$ & $c_{c}$ & $m_{c}$ & $X_{c}$ & $V_{a}$ & $c_{c}$ \\
\hline Unit & $\mathrm{kg} / \mathrm{s}$ & $\%$ & $\mathrm{~m}^{3} / \mathrm{s}$ & $\mathrm{kg} / \mathrm{m}^{3}$ & $\mathrm{~kg} / \mathrm{s}$ & $\%$ & $\mathrm{~m}^{3} / \mathrm{s}$ & $\mathrm{kg} / \mathrm{m}^{3}$ & $\mathrm{~kg} / \mathrm{s}$ & $\%$ & $\mathrm{~m}^{3} / \mathrm{s}$ & $\mathrm{kg} / \mathrm{m}^{3}$ \\
\hline HCS & 2.036 & 62.1 & & & 0.976 & 59.51 & & & 3.191 & 64.85 & & \\
\hline LCS & 1.244 & 37.9 & 15.21 & 0.216 & 0.664 & 40.49 & 7.6 & 0.216 & 1.729 & 35.14 & 22.82 & 0.216 \\
\hline Sum & 3.28 & 100 & & & 1.64 & 100 & & & 4.92 & 100 & & \\
\hline
\end{tabular}

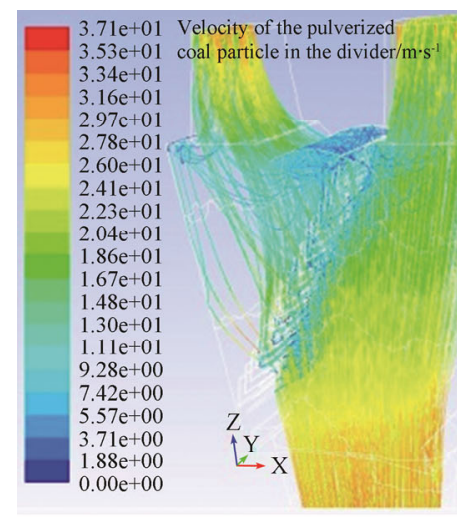

(a)

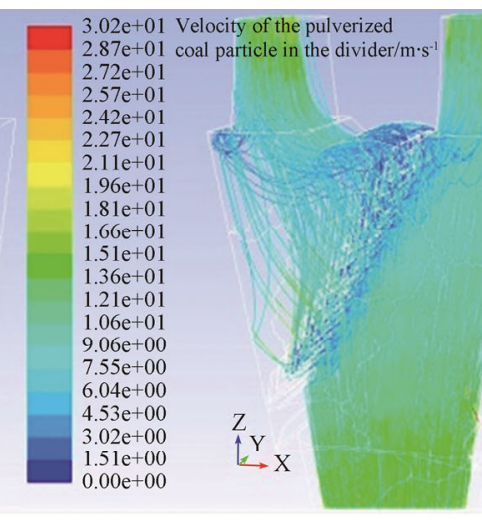

(b)

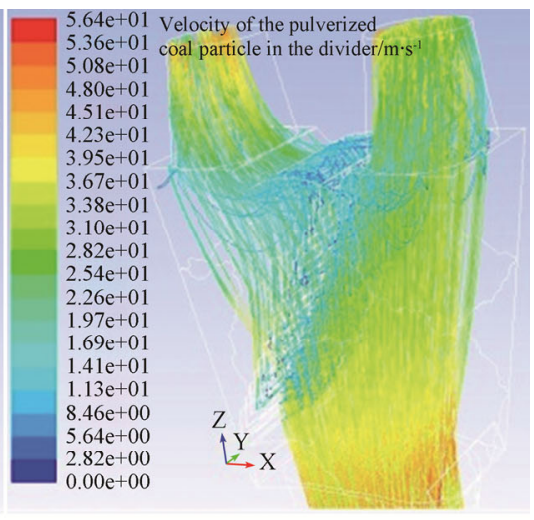

(c)

Fig. 22 Velocity of the pulverized coal particle in the divider (a) $w_{n}=20 \mathrm{~m} / \mathrm{s}$, (b) $w_{n}=10 \mathrm{~m} / \mathrm{s}$, (c) $w_{n}=30 \mathrm{~m} / \mathrm{s}$

Table 8 Final results of CFD modelling of proposition of dividers modernization

\begin{tabular}{ccccccccccccccc}
\hline Case & 1 & 2 & 3 & 4 & 5 & 6 & 7 & 8 & 9 & $10 \mathrm{a}$ & $10 \mathrm{~b}$ & 11 & 12 \\
\cline { 2 - 6 } & $\Delta X_{c H C S}$ & $\Delta X_{c H C S}$ & $\Delta X_{c H C S}$ & $\Delta X_{c H C S}$ & $\Delta X_{c H C S}$ & $\Delta X_{c H C S}$ & $\Delta X_{c H C S}$ & $\Delta X_{c H C S}$ & $\Delta X_{c H C S}$ & $\Delta X_{c H C S}$ & $\Delta X_{c H C S}$ & $\Delta X_{c H C S}$ & $\Delta X_{c H C S}$ \\
Data & $\%$ & $\%$ & $\%$ & $\%$ & $\%$ & $\%$ & $\%$ & $\%$ & $\%$ & $\%$ & $\%$ & $\%$ & $\%$ \\
\hline Value & -0.8 & -2.23 & 1.31 & 6.1 & 0.65 & 0.85 & 1.58 & 5.76 & 11.74 & -2.59 & 2.75 & 3.32 & 3.78 \\
Rating & 11 & 12 & 8 & 2 & 10 & 9 & 7 & 3 & 1 & 13 & 6 & 5 & 4 \\
\hline
\end{tabular}

In order to preserve the comparability of the results, i.e. the concentration of pulverized coal in the air $C c$ as for the base case, the sum of the mass flow of pulverized coal for Cases 10a and 10b (Table 7) must be different from the base one, because changing the velocity at the inlet $w_{n}$ changes mass flow. In Table 7 volumetric flow of air $V_{a}$ are also included.

In Table 8 the final results of CFD modeling of the proposition of modernized dividers was presented. Here $\Delta X_{c H C S}$ marked the percentage difference of the distribution of pulverized coal for the concentrated outlet. The base value for determining $\Delta X_{c H C S}$ was the value obtained for Case 2 from Table 4. Minus means a worsening of the distribution compared to the base case before modernization. The most effective case (i.e., the case that had the maximal mass fraction of pulverized coal at the concentrated outlet) in this paper was found to be Case 9. Case 4 gave good results by decreasing the angle between the shutters. Cases 11 and 12 were less advantageous but also achieved good results. Decreasing the interval between blades $s$, increasing the width of the blades $b$, and decreasing the angle between blades /gives the best results, as shown in Case 9.

\section{Conclusions}

Field study of the existing and working shutter divider of pulverized coal were carried out to validate the numerical model. The field tests of the distributor also allowed the identification of the modernization direction to improve the distribution of the pulverized coal fraction. On this basis, it became possible to conduct numerical tests on the modernization of the distributor. It was indicated which case in terms of the objective criterion (maximizing the pulverized coal distribution for the concentrated outlet) proved to be the most effective. Therefore, the work also presents a procedure to carry out numerical tests for the modernization of a fluid separator. It is impossible to carry out numerical calculations of the distributor modernization without earlier field tests. 


\section{References}

[1] Zhou Z., Liu X., Zhao B., Chen Z., Shao H., Wang L., Xu M., Effects of existing energy saving and air pollution control devices on mercury removal in coal-fired power plants. Fuel Processing Technology, 2015, 131: 99-108.

[2] Andrić I., Jamali-Zghal N., Santarelli M., Lacarrière B., Le Corre O., Environmental performance assessment of retrofitting existing coal fired power plants to co-firing with biomass: carbon footprint and energy approach. Journal of Cleaner Production, 2015, 103: 13-27.

[3] Bhuiyan A.A, Naser J., CFD modelling of co-firing of biomass with coal under oxy-fuel combustion in a large scale power plant. Fuel, 2015, 159: 150-168.

[4] Czakiert T., Bis Z., Muskala W., Nowak W., Fuel conversion from oxy-fuel combustion in a circulating fluidized bed. Fuel Processing Technology, 2006, 87: 531-538.

[5] Ciukaj S., Influence of combined coal and biomass co-firing in pulverized fuel boilers (Wpływ współspalania biomasy na pracę kotłów pyłowych - in polish). PhD thesis. Silesian University of Technology, Gliwice, Poland, 2012.

[6] Wei Z., Li X., Xu L., Cheng Y., Comparative study of computational intelligence approaches for $\mathrm{NO}_{x}$ reduction of coal-fired boiler. Energy, 2013, 55: 683-692.

[7] Rusinowski H., Stanek W., Hybrid model of steam boiler. Energy, 2010, 35: 1107-1113.

[8] Lv Y., Liu J., Yang T., Zeng D., A novel least squares support vector machine ensemble model for $\mathrm{NO}_{x}$ emission prediction of a coal-fired boiler. Energy, 2013, 55: 319-329.

[9] Pronobis M., Modernizacja kotłów energetycznych [Modernisation of power boilers], WNT, Warsaw, Poland, 2002.

[10] Ferrín J.L., Saavedra L., Distribution of the coal flow in the mill-duct system of the As Pontes Power Plant using CFD modeling. Fuel Processing Technology, 2013, 106: 84-94.

[11] Wang Q., Melaaen M.C., De Silva S.R., Investigation and simulation of a cross-flow air classifier. Powder Technology, 2001, 120: 273-280.

[12] Johansson R., Evertsson M., CFD simulation of a gravitational air classifier. Minerals Engineering, 2012, 33: 20-26.

[13] Vuthaluru H.B., Pareek V.K., Vuthaluru R., Multiphase flow simulation of a simplified coal pulveriser. Fuel Processing Technology, 2005, 86: 1195-1205.

[14] Sommerfeld M., Huber N., Experimental analysis and modelling of particle-wall collisions. International Journal of Multiphase Flow, 1999, 25: 1457-1489.
[15] Afolabi L., Aroussi A., Mat Isa N., Numerical modelling of the carrier gas phase in a laboratory-scale coal classifier model. Fuel Processing Technology, 2011, 92: 556-562.

[16] Wallace M.S., Peters J.S., et al., CFD based erosion modelling of multi-orifice choke valve. Proceedings of 2000 ASME Fluids Engineering Summer Meeting, Boston, MA, 2000, 2: 945-958.

[17] Shirazi S.A., Shadley J.R., Mclaury B.S., A procedure to predict solid particle erosion in elbows and tees. Journal of Pressure Vessel Technology, 1995, 117: 45-52.

[18] Edwards J.K., McLaury B.S., Shirazi S.A., Supplementing a CFD code with erosion prediction capabilities. In Proceedings of ASME FEDSM'98: ASME 1998 Fluids Engineering Division Summer Meeting, vol. 245, Washington D.C. 1998.

[19] Sciubba E., Zeoli N., A study of sootblower erosion in waste-incinerating heat boilers. Journal of Energy Resources Technology, 2007, 129: 50-53.

[20] Vuthaluru H.B., Pareek V.K., Vuthaluru R., Multiphase flow simulation of a simplified coal pulveriser. Fuel Processing Technology, 2005, 86: 1195-1205.

[21] Kozić M., Ristić S., Puharić M., Linić S., CFD analysis of the influence of centrifugal separator geometry modification on the pulverized coal distribution at the burners. Transactions of FAMENA, 2014, 38: 25-36.

[22] Hernik B., Pronobis M., Wejkowski R., Wojnar W.: Experimental verification of a CFD model intended for the determination of restitution coefficients used in erosion modelling. E3S Web of Conference, 2017, 13: article number 05001. (doi.org/10.1051/e3sconf/ 20171305001).

[23] Hernik B., Wejkowski R., Ciukaj Sz., Comparison of accuracy of the naphthalene analogy method and CFD modelling in determining the convective heat transfer coefficient in combined-diagonally finned and plain tube bank. Papers of the 7th International Conference, Economical Energy Production, Transfer, and Consumption. Acta Mechanica Slovaca, 2007, 11(4-D): 297-302.

[24] Picart A., Berlemont A., Gouesbet G., Modelling and predicting turbulence fields and the dispersion of discrete particles transported by turbulent flows. International Journal of Multiphase Flow, 1986, 12: 237-261.

[25] Shih T., Liou W.W., Shabbir A., A new k- $\varepsilon$ eddy viscosity model for high Reynolds number turbulent flows - model development and validation. Computers and Fluids, 1995, 24: $227-238$

[26] Hernik B., Investigations for decreasing of risk of corrosion-erosion in boilers (Badania dla zmniejszenia zagrożenia korozyjno-erozyjnego kotłów energetycznych -in polish). PhD thesis. Silesian University of Technology, Gliwice, Poland, 2009. 